\title{
Histopathology of viremia-associated ana-aki-byo in combination with Aeromonas hydrophila in color carp Cyprinus carpio in Japan
}

\author{
Teruo Miyazaki ${ }^{1, *}$, Tetsushi Kageyama ${ }^{1}$, Masayuki Miura ${ }^{1}$, Toyoteru Yoshida $^{2}$ \\ ${ }^{1}$ Faculty of Bioresources, Mie University, 1515 Kamihama, Tsu, Mie 514-8507, Japan \\ ${ }^{2}$ Faculty of Agriculture, Miyazaki University, 1-1-1 Gakuen-kihanadai-nishi, Miyazaki, Miyazaki 889-2192, Japan
}

\begin{abstract}
A disease in which 'viremia-associated ana-aki-byo' is combined with an Aeromonas hydrophila infection currently occurs and is highly transmissible in color carp Cyprinus carpio in Japan. In the present study, to determine the interrelation between a corona-like virus and $A$. hydrophila, we conducted transmission trials by cohabiting naturally diseased carp with healthy carp with skin that had been slightly damaged artificially. Experimentally exposed fish successfully replicated the combination of a corona-like viral viremia and A. hydrophila infection. Diseased carp displayed scale-sac edema, ascites and exophthalmus adding to the formation of skin ulcers. In addition to pathological changes due to the corona-like virus infection, various changes due to the $A$. hydrophila infection occurred. Anasarcous skin lesions exhibited a separated epidermis, expanded scale-sacs, and an edematous dermis accompanied by hemorrhage and necrosis. The underlying lateral musculature was edematous and possessed markedly atrophied muscle fibers. Hepatocytes were either atrophied or swollen and had a granular appearance. Renal tubular cells showed vacuolar degeneration, cloudy swelling, necrosis and destruction. Hemosiderin deposition occurred within macrophages in the spleen and hematopoietic tissue, and within hepatocytes. Cardiac muscle fibers exhibited degeneration and necrosis accompanied by hemorrhage in the myocardium of heart. These changes appeared to be induced by bacterial toxins because bacterial cells did not directly invade these affected tissues.
\end{abstract}

KEY WORDS: Viremia · Corona-like virus · Aeromonas hydrophila · Carp · Skin ulcer · Anasarca · Nephroses Resale or republication not permitted without written consent of the publisher

\section{INTRODUCTION}

A new viral disease, 'viremia-associated ana-akibyo', was recently reported to be prevalent in color carp Cyprinus carpio in Japan (Miyazaki et al. 2000). We determined that diseased carp that were primarily suffering from a viremia with corona-like virus (CLV) were also affected by secondary invasions of water-borne bacteria, resulting in the formation of skin ulcers. However, CLV is known to be lethal to carp by itself.

In 1999, diseased carp which displayed scale-sac edema, exophthalmus and ascites as well as the forma-

*E-mail: miyazaki@bio.mie-u.ac.jp tion of skin ulcers were often observed. In addition to isolation of CLV from the dermal lesions and the visceral organs, Aeromonas hydrophila was isolated from edematous scale-sacs, ulcerative lesions and ascitic fluid. Such a combination of a CLV viremia with an $A$. hydrophila infection was not unexpected, as it has been known to occur before. It has been well known that diseased carp with 'spring viremia of carp' (Rhabdovirus carpio infection, Fijan et al. 1971) are often infected with $A$. hydrophila as well. The complex infection was called 'infectious dropsy' (Fijan 1972), although the interrelation between the virus and bacterium, and its histopathological features have not been completely determined. 
In the present study, this complex disease was found to be highly transmissible in carp groups reared in ponds. Therefore, we conducted transmission studies to determine how the virus and bacteria are transmitted by cohabiting the naturally diseased carp with healthy carp whose skin had been damaged slightly. As result, the combined infection was successfully replicated. Here pathological features of this complex disease and the interrelation between CLV and Aeromonas hydrophila are determined through histological and electron microscopic examinations of diseased fish.

\section{MATERIAL AND METHODS}

Diseased carp and healthy carp. Diseased carp (3 yr old, 200 to $300 \mathrm{~g}$ ) appeared in fish groups which were reared in a cold spring (around $20^{\circ} \mathrm{C}$ ) from June to July 1999 and usually displayed anasarcous signs in addition to skin ulceration. Five diseased fish were collected in June for histopathological examinations and for viral and bacterial isolation. In July, 16 diseased fish were collected again from the same fish groups and used as donors for transmission experiments. For the experiments, healthy carp ( 2 and 4 yr old) were obtained from ponds which had never experienced 'viremia-associated ana-aki-byo'. These fish were immediately treated with $50 \mathrm{ppm}$ formalin solution for $24 \mathrm{~h}$ in order to remove parasites from the skin and gills.

Transmission experiments by cohabitation. Two naturally diseased carp with skin ulcers were placed in each of 6 aquaria $(30 \mathrm{l})$ with aeration at $20^{\circ} \mathrm{C}$, and the remaining diseased fish were stocked in plastic tanks $\left(300 \mathrm{l}\right.$ at $\left.20^{\circ} \mathrm{C}\right)$. When a diseased fish died in an aquarium, it was removed and replaced by another diseased fish from the stock group during the experimental period. Before cohabitation, healthy carp (2 yr old, 40 to $70 \mathrm{~g}$ ) were slightly injured by removing several scales from the peduncle on the left side of the body. In each aquarium, 3 or 4 of these experimentally challenged fish were cohabited with 2 naturally diseased fish. When the experimental fish became moribund, they were immediately removed and replaced by new experimental fish. During this experiment, a total of 30 experimental fish experienced the cohabitation experiment. As the control, 6 healthy fish (2 yr old, $50 \mathrm{~g}$ ) whose skin had been damaged in the same manner as the experimental fish were held with a healthy carp (3 yr old, size similar to the naturally diseased fish) for $30 \mathrm{~d}$ at $20^{\circ} \mathrm{C}$.

Isolation of virus and bacteria. Isolation of CLV was attempted from naturally diseased fish and experimentally diseased fish according to Miyazaki et al. (2000). Bacterial isolation was performed from ulcerative lesions, edematous scale-sacs, ascitic fluid and the kidney using heart infusion agar plates at $20^{\circ} \mathrm{C}$ for $3 \mathrm{~d}$. For most of the samples from edematous scale-sacs, ascitic fluid and the kidney, a single type of bacterium which was identified as Aeromonas hydrophila by Api 20 tests grew on the agar plates. This bacterium demonstrated a hemolytic activity on sheep-blood agar plates. Some colonies that showed prominent homolysis were selected for artificial infections.

Artificial infections with Aeromonas hydrophila. The pathogenicity of CLV has been described in our previous study (Miyazaki et al. 2000). Here, the pathogenicity of the isolated Aeromonas hydrophila was examined. The organism was cultured in heart infusion broth (HI broth) at $20^{\circ} \mathrm{C}$ for $48 \mathrm{~h}$. The culture was centrifuged at $3000 \times g$ for $15 \mathrm{~min}$ and the cell pellet was resuspended in saline. A bacterial suspension $(0.5 \mathrm{ml})$ was injected under the skin of 10 carp at a dose of $7.8 \times$ $10^{4.0} \mathrm{CFU} \mathrm{m} \mathrm{m}^{-1}$. For a control, 5 carp were injected with the same amount of sterile saline. As noted later, the bacterium cultured in $\mathrm{HI}$ broth did not cause disease. We attempted to culture the bacterium in Luria-Bertani broth (LB broth for culturing Escherichia coli; bactotryptone $10 \mathrm{~g}$, yeast extract $5 \mathrm{~g}, \mathrm{NaCl} 5 \mathrm{~g}$, water $1000 \mathrm{ml}$ ) supplemented with $5 \%$ carp serum which was provided from a healthy carp (4 yr old, $2 \mathrm{~kg}$ ). LB broth was used because A. hydrophila was often found to multiply in digested material inside the intestine of diseased goldfish Carassius auratus (Kubota et al. 1981), crucian carp Carassius auratus (Miyazaki \& Kaige 1986) and Japanese eel Anguilla japonica (Egusa 1978, Miyazaki 1980, Kubota et al. 1981), as well as of healthy fishes (Sorimachi \& Egusa 1971, Aoki 1974, 1975, Kanai et al. 1977). Thus, in this respect, A. hydrophila resembles E. coli. Furthermore, A. hydrophila appeared to grow in the fluid contained in the scalesacs and ascitic fluid of diseased carp. Therefore, we introduced LB broth as a base medium and supplemented it with carp serum. The bacterium grew well in this medium at $20^{\circ} \mathrm{C}$ for $48 \mathrm{~h}$. The bacterial suspension was prepared again, and $0.5 \mathrm{ml}$ was injected either under the skin of 5 carp at a dose of $2.6 \times 10^{5.0} \mathrm{CFU} \mathrm{ml}^{-1}$ or $1 \mathrm{ml}$ was injected into the abdominal cavity of 6 carp at a dose of $5.2 \times 10^{5.0} \mathrm{CFU} \mathrm{ml}^{-1}$. Two control groups were established, one for each type of injection in which 5 fish were injected with the same amount of sterile saline and held in aquaria with aeration and feeding at $20^{\circ} \mathrm{C}$. The fish were observed for $30 \mathrm{~d}$ and then sampled for histopathological examinations. None of the injected fish died during the observation period.

Histopathological and electron microscopic examinations. Sampled fish were dissected after external and internal examination while they were anesthetized with $1.5 \%$ urethane solution. Pieces of the dermal le- 
sions and visceral organs were fixed in $10 \%$ phosphate-buffered formalin solution for histological evaluation. The fixed tissues were prepared according to standard techniques and stained with hematoxylin \& eosin (H\&E), Azan, Giemsa (for bacteria), Berlin blue (for hemosiderin) and Periodic acid Schiff (PAS) reaction. Pieces of the remaining dermal lesion, heart, spleen and kidney were fixed in $70 \%$ Karnovsky solution, postfixed in $1 \% \mathrm{OsO}_{4}$ and processed for electron microscopy (EM) according to standard techniques.

\section{RESULTS}

\section{Diseased fish in a natural outbreak}

Naturally diseased carp had a pinecone appearance (edematous scale-sacs) accompanied by intracutaneous hemorrhage and dilated capillaries, exophthalmus and an expanded abdomen due to ascites in addition to the formation of skin ulcers (Fig. 1A). The diseased fish gradually developed the above anasarcous changes and were often alive as long as 10 to $14 \mathrm{~d}$ after the occurrence of skin ulcers. The abdominal cavity contained clear or bloody ascitic fluid. The liver, spleen, kidney and gills showed pale coloration. In some fish, the intestine and spleen were hemorrhagic. The lateral musculature was markedly edematous and contained cloudy or whitened muscle fibers. In all of the diseased fish, pure cultures of Aeromonas hydrophila were isolated from edematous scale-sacs and ascitic fluid, and A. hydrophila mixed with other bacteria were isolated from ulcerative lesions of the skin. The virus that caused the same cytopathic effect as Miyazaki et al. (2000) was successfully isolated from the examined ulcerative skin, spleen, kidney and heart.

Histopathological signs of the ulcerative lesions were mostly the same as those of 'viremia-associated anaaki-byo' (Miyazaki et al. 2000). However, in the region displaying edematous scale-sacs and intracutaneous hemorrhage, there were expanded scale-sacs, a separated epidermis, and dermal loose connective tissue that showed deposition of fibrin on the upper layer around the scale-sacs, hemorrhage, necrotic fibrocytes and dilated capillaries containing lysed erythrocytes. The underlying dermal dense connective tissue was also edematous. The subcutaneous adipose tissue showed hemorrhage and infiltration of inflammatory cells. The lateral musculature was markedly edematous and hemorrhagic, and possessed muscle fibers that were extensively atrophied and fragmented (Fig. 2A). However, Giemsa staining showed that bacterial cells in these lesions were not significantly multiplying although bacteria were isolated from edematous scalesacs. In EM of dermal lesions, endothelial cells of capillaries (Fig. 2B) and fibrocytes (Fig. 2D) displayed many particles of CLV accompanied by the formation of electron-dense inclusions but no tubular strictures in the cytoplasm. Furthermore, many capillaries possessed necrotic endothelial cells showing a degenerated nucleus, degenerated mitochondria, a lot of small clumpy matter and the poorly defined basal membrane. Therefore, the capillaries were partially damaged and allowed erythrocytes to leak from the capillaries (Fig. 2C). The collagen fibers around these
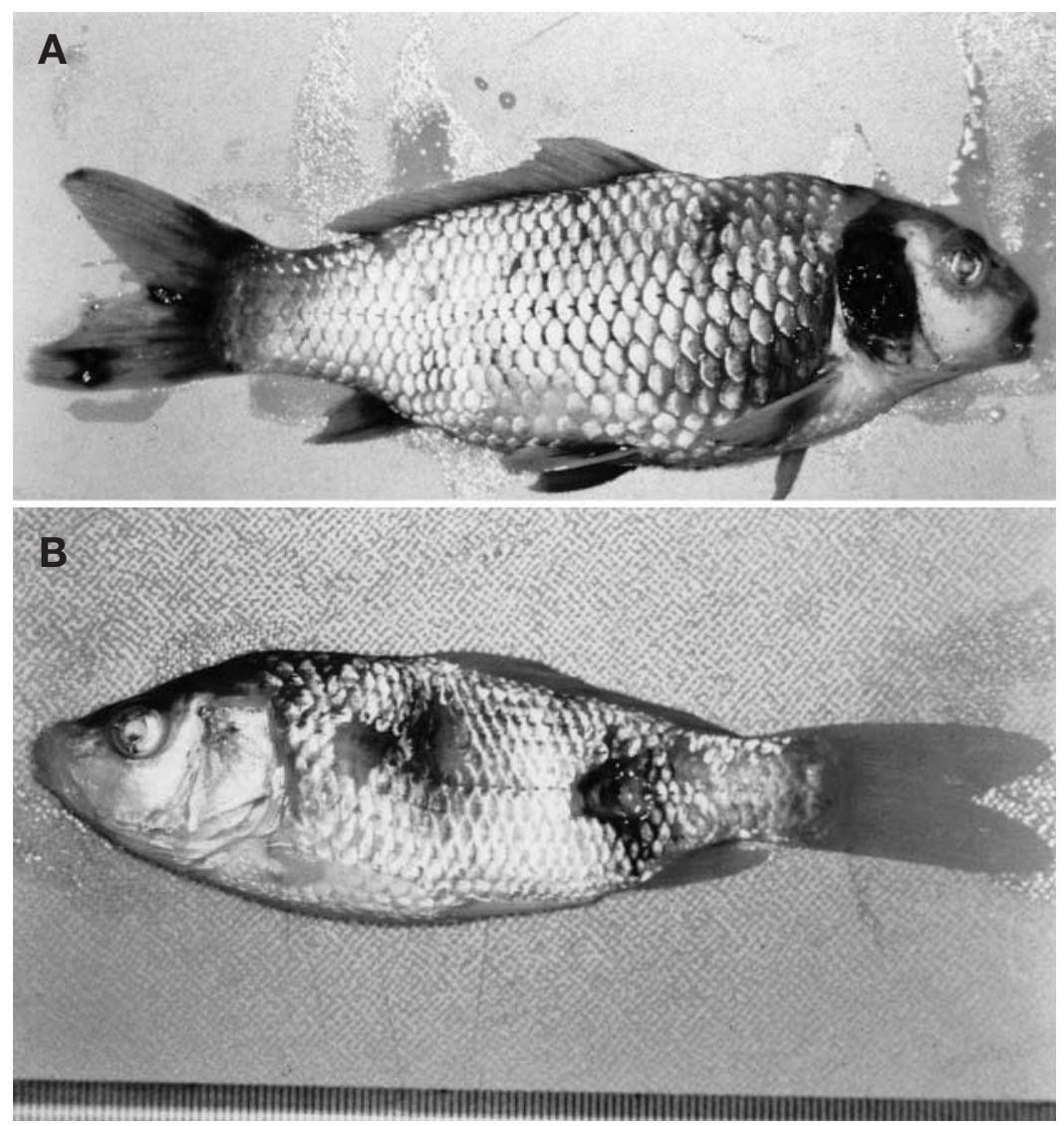

Fig. 1. Cyprinus carpio. (A) Naturally diseased carp displays ulcerative lesions in the snout, opercle and caudal fin, scale-sac edema, intracutaneous hemorrhage, ascites and exophthalmus. (B) Experimentally diseased carp by cohabitation with naturally diseased fish. This fish shows skin ulcers at a wounded site on the peduncle and the body accompanied by hemorrhage and edematous scale-sacs 


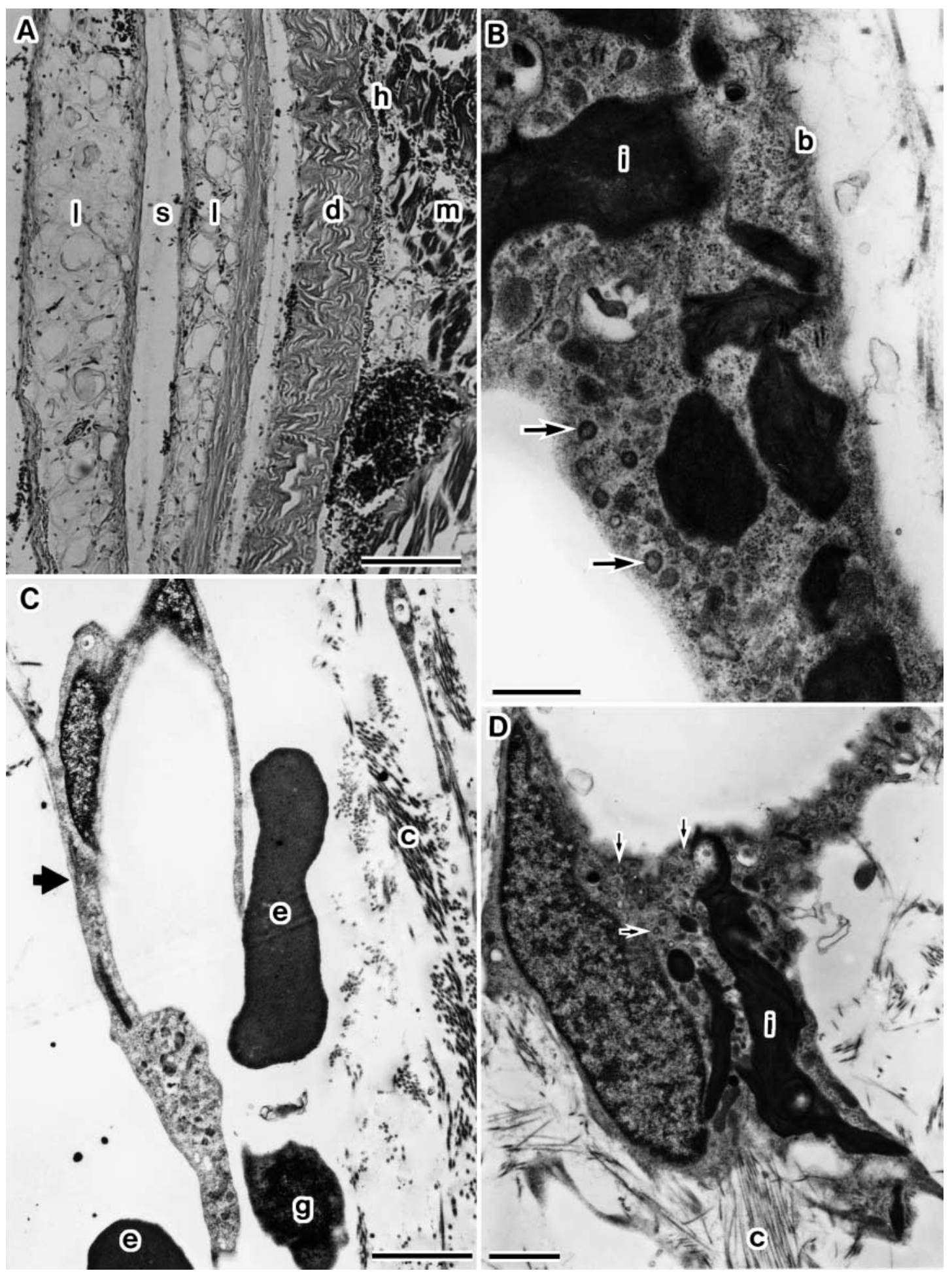

Fig. 2. Cyprinus carpio in a natural outbreak. (A-D) Edematous lesions in the skin. (A) Edematous lesion of the skin. The epidermis is separated. The underlying dermal loose connective tissue is highly edematous and accompanied by slight hemorrhage. Hemorrhagic lesions occur in the subcutaneous adipose tissue and the lateral musculature. H\&E. Scale bar $=200 \mu \mathrm{m}$. (B) Electron micrograph of an endothelial cell of a dermal capillary. Many corona-like virus (CLV) particles (arrows) appear accompanied by the formation of electron-dense materials containing crystalline inclusions. The basal membrane is poorly defined. Scale bar $=$ $1 \mu \mathrm{m}$. (C) Electron micrograph of a dermal capillary possessing the necrotic endothelial cell and the uncleared basal membrane. The capillary (arrow) is partially damaged and allows erythrocytes to leak out of the capillaries. Scale bar $=2.5 \mu \mathrm{m}$. (D) Electron micrograph of a dermal fibrocyte. Many CLV particles (arrows) and electron-dense material appear in a cytoplasm. Scale bar $=2$ $\mu \mathrm{m}$. b: basal membrane; c: collagen fibers; d: dermal dense connective tissue; e: erythrocytes; g: granulocyte; h: hemorrhage; i: electron-dense materials containing crystalline inclusions; 1: dermal loose connective tissue; m: lateral musculature; s: scale-sac 
affected capillaries were edematously separated and showed a poorly defined banding pattern. The underlying lateral musculature contained many muscle fibers showing fragmented myofibrils, degenerated mitochondria and expanded endoplasmic reticula.

In the ventricle and auricle of the heart, cardiac muscle fibers contained fragmented myofibrils in a state of vacuolar degeneration, or contained coagulated myofibrils in a state of atrophy within the inner layer of the myocardium. In the outer layer of myocardium, hemorrhage sometimes occurred among damaged muscle fibers (Fig. 3A). Small clots of erythrocytes were formed on the endocardium and within the lumen. In some fish, the lumen contained many nuclei which were derived from lysed erythrocytes. The epicardium showed hemorrhage and infiltration of inflammatory cells around expanded blood vessels. However, there was no evidence of any active multiplication of bacterial cells in these necrotic lesions in the heart. In EM of cardiac muscle fibers, the affected fibers usually possessed fragmented myofibril bundles, many degenerated mitochondria, and almost no glycogen granules (Fig. 3B). In these bundles, myofibrils were markedly fragmented and disarranged, or were lysed accompanied by a swollen banding pattern. Degenerated mitochondria displayed 2 different types of damage: either expanded or coagulated. Expanded mitochondria usually displayed a round shape, damaged cristae and absent matrix. In coagulated mitochondria, most cristae disappeared and were replaced with amorphous materials. Many matrical electrondense granules of divalent cations were prominently deposited in these damaged mitochondria. Vacuolized muscle fibers possessed much empty space, expanded smooth endoplasmic reticula (sER) and small numbers of CLV particles in the myoplasm, while atrophic muscle fibers had tight myoplasms in which CLV particles were usually difficult to observe.

In the liver, hepatocytes were either atrophied or swollen and had a granular appearance (Fig. 3C). There were small numbers of hepatocytes showing deposition of hemosiderin granules and hemosiderinladen macrophages in sinusoids. The hemosiderin granules were dark blue with Berlin blue stain. In EM of hepatocytes with cloudy swelling, they possessed expanded nuclei displaying marginal deposition of chromatin, markedly expanded mitochondria with destroyed cristae, fragmented and expanded rough endoplasmic reticula (rER), no glycogen granules, and no CLV particles in an electron-lucent cytoplasm (Fig. 3D). Some expanded rER contained electron-dense materials. Atrophied hepatocytes possessed small numbers of coagulated mitochondria, many fragmented rER, hemosiderin inclusions with high electron-dense fine granules and no glycogen granules.
In the spleen, many necrotic cells occurred in the pulps and sheathed tissues accompanied by fibrin deposition. Most spleens included many macrophages showing erythrocyte-phagocytosis and deposition of hemosiderin or ceroid (Fig. 4A). In EM of the spleen, reticular cells in the sheathed tissues contained many masses of electron-dense fine granules of hemosiderin (Fig. 4B). Reticular cells in the sheathed tissues and lining sinusoids were necrotized and displayed many particles of CLV, many tubular strictures, electrondense materials containing crystalline inclusions, and expanded endoplasmic reticula in an electron-lucent cytoplasm (Fig. 4C).

In the kidney, renal tubular epithelial cells displayed cloudy swelling, vacuolar degeneration accompanied by nuclear degeneration, and necrosis followed by tubular destruction (Fig. 4D). Sometimes these affected tubular cells, like normal-looking tubular cells, contained hemosiderin granules. Glomeruli contained necrotic cells and sometimes were partially destroyed. These necrotic lesions did not show any evidence of bacterial invasions. In EM, vacuolized tubular cells showed large empty spaces, rounded and degenerated mitochondria, and expanded reticula in an electronlucent cytoplasm (Fig. 5A). Tubular cells with coagulative necrosis exhibited condensed mitochondria in which the cristae were not visible, and deposition of many matrical electron-dense granules of divalent cations in the entire cell (Fig. 5B). Furthermore, necrotic tubular cells had expanded mitochondria with markedly fragmented cristae and expanded rER in the electronlucent cytoplasm (Fig. 5C). Thus, these affected tubular cells did not display any particles of CLV in the cytoplasm or any bacterial cells around the tubular cells. In the hematopoietic tissue, there were extensively necrotized cells and small numbers of macrophages showing erythrocyte-phagocytosis and hemosiderin deposition. In EM, various kinds of cells were necrotized and showed many particles of CLV, electron-dense materials containing crystalline inclusions and tubular structures in an electron-lucent cytoplasm.

In most gills, the respiratory epithelia and interlamellar epithelia were edematously separated. Exophthalmic eyes displayed hemorrhage and edematous dilation in the choroidal membrane. In some fish, the intestine contained large numbers of necrotized cells in the epithelium and hemorrhage in the tunica propria.

\section{Transmission experiments by cohabitation}

A total of 30 experimental carp experienced cohabitation with naturally diseased carp and 28 of them either died or became moribund between Day 4 and Day 28 (Fig. 6). Only 2 were alive without any patho- 

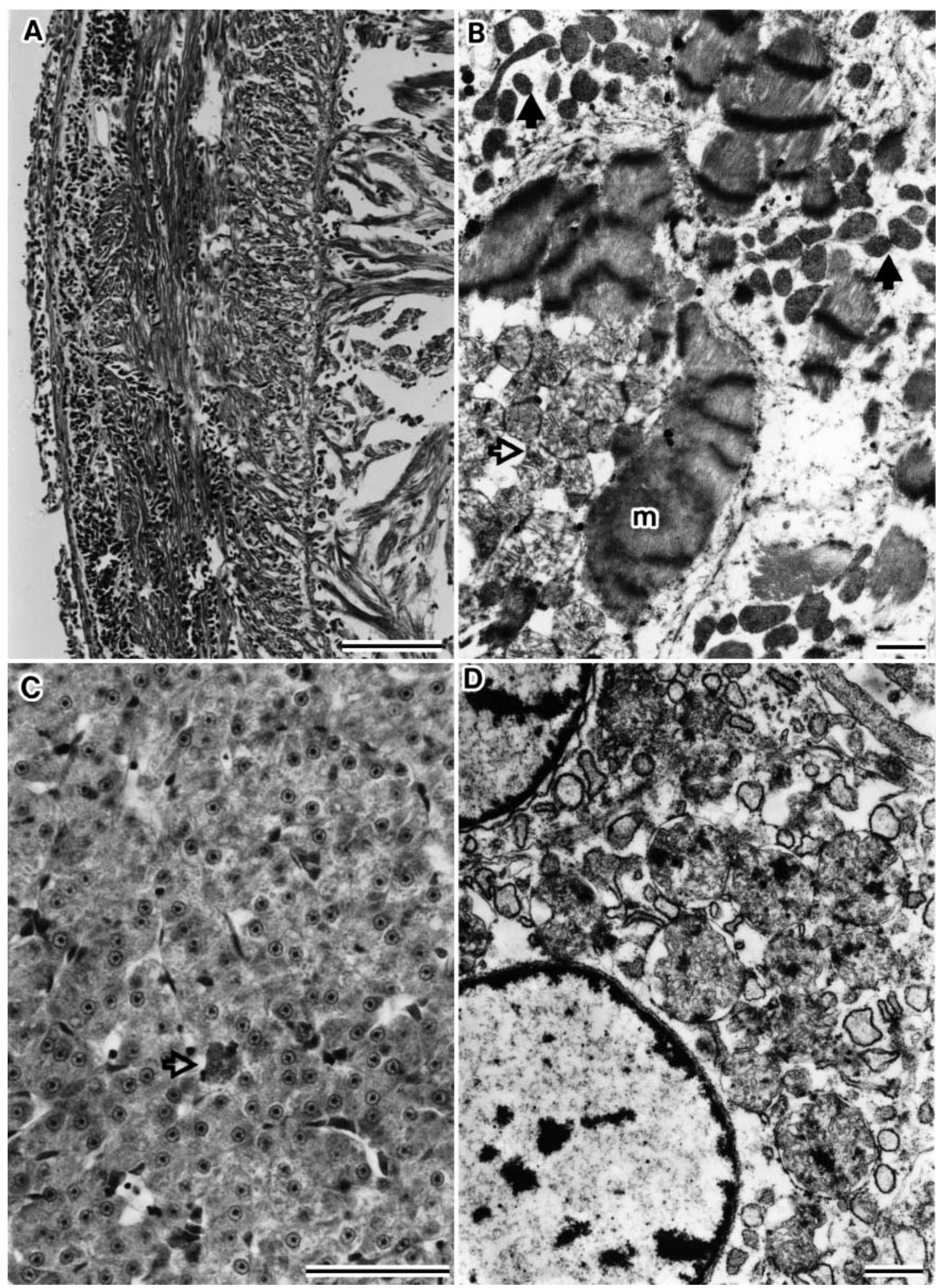

Fig. 3. Cyprinus carpio in a natural outbreak. (A) In the outer layer of myocardium, hemorrhage occurs among damaged muscle fibers. Cardiac muscle fibers in the inner layer are highly vacuolized. H\&E. Scale bar $=100 \mu \mathrm{m}$. (B) Electron micrograph of cardiac muscle fibers $(\mathrm{m})$. Bundles of myofibrils are fragmented showing the swollen banding pattern. An open arrow shows many mitochondria that were swollen with destroyed cristae. Black arrows show many coagulated mitochondria. Glycogen granules disappeared in a highly vacuolized myoplasm. Scale bar $=1 \mu \mathrm{m}$. (C) In the liver, hepatocytes show a granular appearance and swelling. An arrow points to hemosiderin-laden macrophages in the sinusoid. H\&E. Scale bar $=50 \mu \mathrm{m}$. (D) Electron micrograph of a hepatocyte showing cloudy swelling. The cell possesses 2 expanded nuclei displaying marginal deposition of chromatin, markedly expanded mitochondria with destroyed tubular cristae, fragmented and expanded rough endoplasmic reticula (rER), and no glycogen granules in an electron lucent cytoplasm. Scale bar $=1 \mu \mathrm{m}$ 


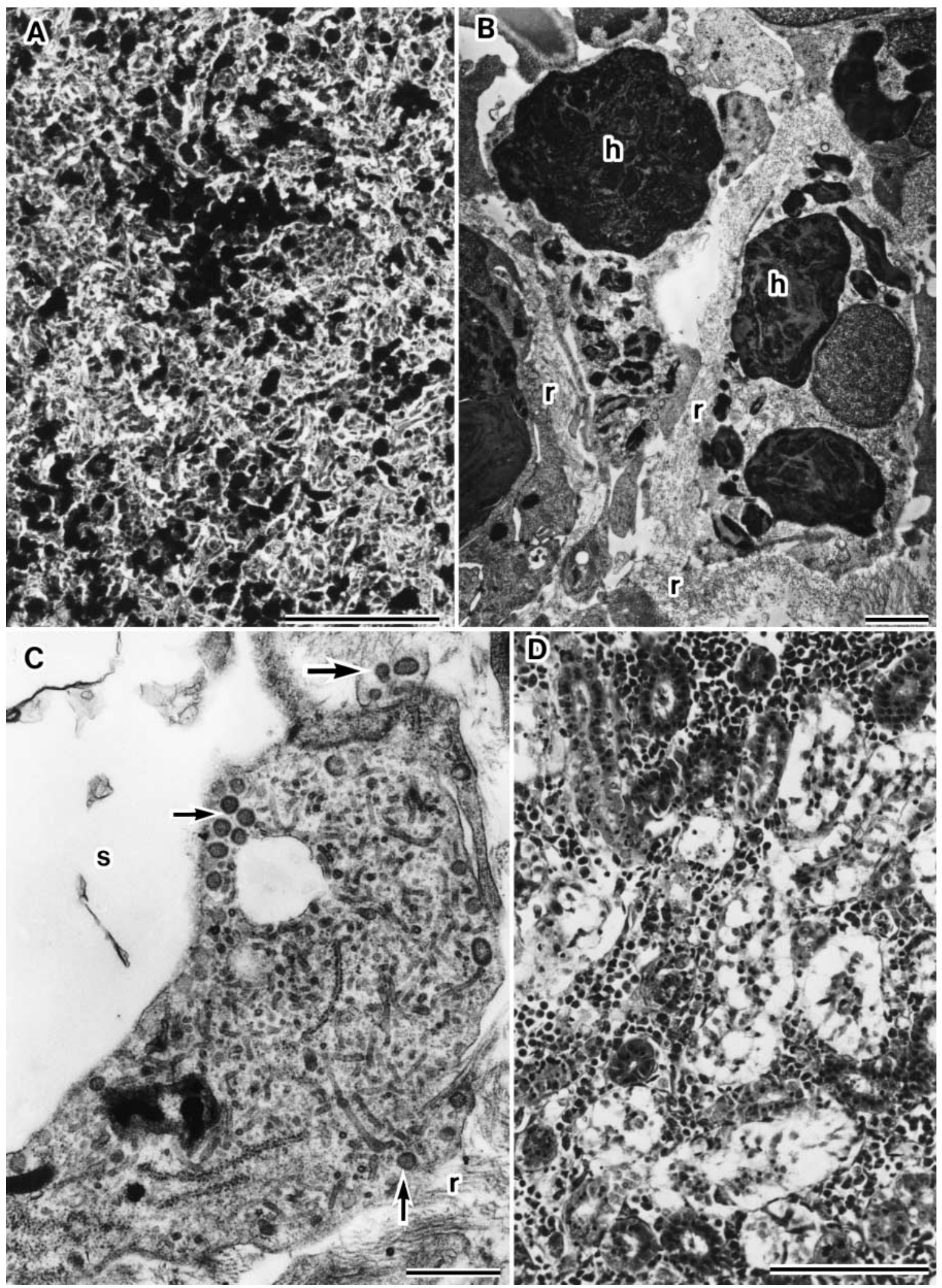

Fig. 4. Cyprinus carpio in a natural outbreak. (A) Spleen includes many macrophages showing erythrocyte-phagocytosis and hemosiderin-deposition that are positive in Berlin blue stain. Scale bar $=100 \mu \mathrm{m}$. (B) Electron micrograph of phagocytizing macrophages in the sheathed tissue of the spleen. They contain many masses of electron-dense fine granules of hemosiderin. Scale bar $=2 \mu \mathrm{m}$. (C) Electron micrograph of a virally infected, reticular cells lining a splenic sinus. Many CLV particles (arrows) and tubular structures appear. Small arrows point to CLV virions in a cytoplasm. A big arrow points to CLV virions that are released from the cell. Scale bar $=900 \mathrm{~nm}$. (D) In the kidney, many tubular epithelial cells display vacuolar degeneration, necrosis and tubular destruction. H\&E. Scale bar $=100 \mu \mathrm{m}$. h: clumps of hemosiderin granules; $\mathrm{r}$ : reticular fibers; s: splenic sinus 



Fig. 5. Cyprinus carpio. (A-C) Naturally diseased fish. (A) Electron micrograph of tubular epithelial cells showing vacuolar degeneration. They show large empty spaces, and rounded and degenerated mitochondria in the electron-lucent cytoplasms. Scale bar $=5 \mu \mathrm{m}$. (B) Electron micrograph of tubular epithelial cells showing coagulative necrosis. They exhibit condensed mitochondria with no cristae, and deposition of many matrical electron-dense granules of divalent cations in the entire cell. Scale bar $=$ $4 \mu \mathrm{m}$. (C) Electron micrograph of tubular epithelial cells showing necrosis. They have a nucleus with marginal chromatosis, expanded mitochondria with fragmented cristae and expanded rER in the electron-lucent cytoplasm. Scale bar $=2 \mu \mathrm{m}$. (D) Electron micrograph of the hematopoietic tissue in an experimentally diseased fish that exhibited no external sign. The necrotized cell contains many CLV particles (arrows). Scale bar $=2 \mu \mathrm{m}$. b: basal membrane of tubular epithelium; c: capillary on renal tubule 
logical change at the end of the experiment. A total of 8 fish were moribund without external signs except for slight hemorrhage only at the wounded site on the peduncle. Five of the 8 fish became moribund between Days 4 and 6, and the other 3 became moribund between Days 10 to 16 . These moribund fish histologically showed many necrotic cells in the spleen and hematopoietic tissues. Their cardiac muscle fibers were atrophic or vacuolized. EM revealed many particles of CLV in necrotic cells of the spleen and hematopoietic tissues (Fig. 5D).

In contrast, a total of 20 fish displayed ulcerative lesions in the skin. In 4 fish, an ulcerative lesion was formed at the wound site and they were moribund on Day 4. The ulcerative lesion showed necrotic dermis that was invaded by many bacterial cells. These fish displayed histopathological changes in the visceral organs that were in most cases similar to those that occurred in moribund fish with no external sign as described above. The remaining 16 fish were moribund after Day 7 and usually displayed skin ulcers not only at the wound site but also at some other sites of the body, scale-sac edema, exophthalmus and ascites (Fig. 1B). The ulcerative lesion displayed histopathological features that were mostly the same as those found in the natural outbreak. Lesions showing scale-sac edema displayed edematous changes and hemorrhage in the dermis and the lateral musculature (Fig. 7A). In ulcerative lesions and edematous lesions, dermal fibrocytes often contained CLV particles. Their visceral organs also exhibited pathological signs that were the same as those in the natural outbreak. Cardiac muscle fibers were either atrophied or vacuolized, and contained CLV particles, fragmented bundles of myofibrils, degenerated mitochondria, expanded sER and no glycogen granules (Fig. 7B). In some fish, the cardiac lumen contained many lytic erythrocytes and the outer layer of the myocardium was hemorrhagic. In the kidney, nephrotic changes in renal tubular cells usually occurred but were moderate compared with those in the natural outbreak (Fig. 7C). In the hematopoietic tissue, necrotic cells that contained many CLV particles, electron-dense materials containing crystalline inclusions, and tubular structures were present (Fig. 7D). Furthermore, macrophages that phagocytized erythrocytes and hemosiderin, and acidophilic granular cells increased in number. The spleens usually contained many necrotic cells and macrophages that phagocytized erythrocytes and hemosiderin. In the liver, hepatocytes showed cloudy swelling and possessed mitochondria with damaged tubular cristae, expanded rER and secondary lysosomes. In most of these 20 fish, Aeromonas hydrophila was isolated from ulcerative lesions or ascitic fluid. CLV was also isolated from the examined spleens

\section{Artificial infection with Aeromonas hydrophila}

All fish that were injected with bacteria that had been cultured both in HI broth and in LB broth with $5 \%$ carp serum did not show any mortality or any pathological changes, even at the injection site of the body during the experimental period. In most fish, the bacterium was not reisolated from the kidney. No marked histological changes occurred in visceral organs of any of the examined fish.

\section{DISCUSSION}

'Viremia-associated ana-aki-byo' is now prevalent in color carp in Japan. We determined that skin ulcerative lesions developed by secondary invasions of waterborne bacteria into the skin that was damaged by a CLV infection in the dermis (Miyazaki et al. 2000). A combined infection with Aeromonas hydrophila occurs and diseased carp display scale-sac edema, exophthal- 


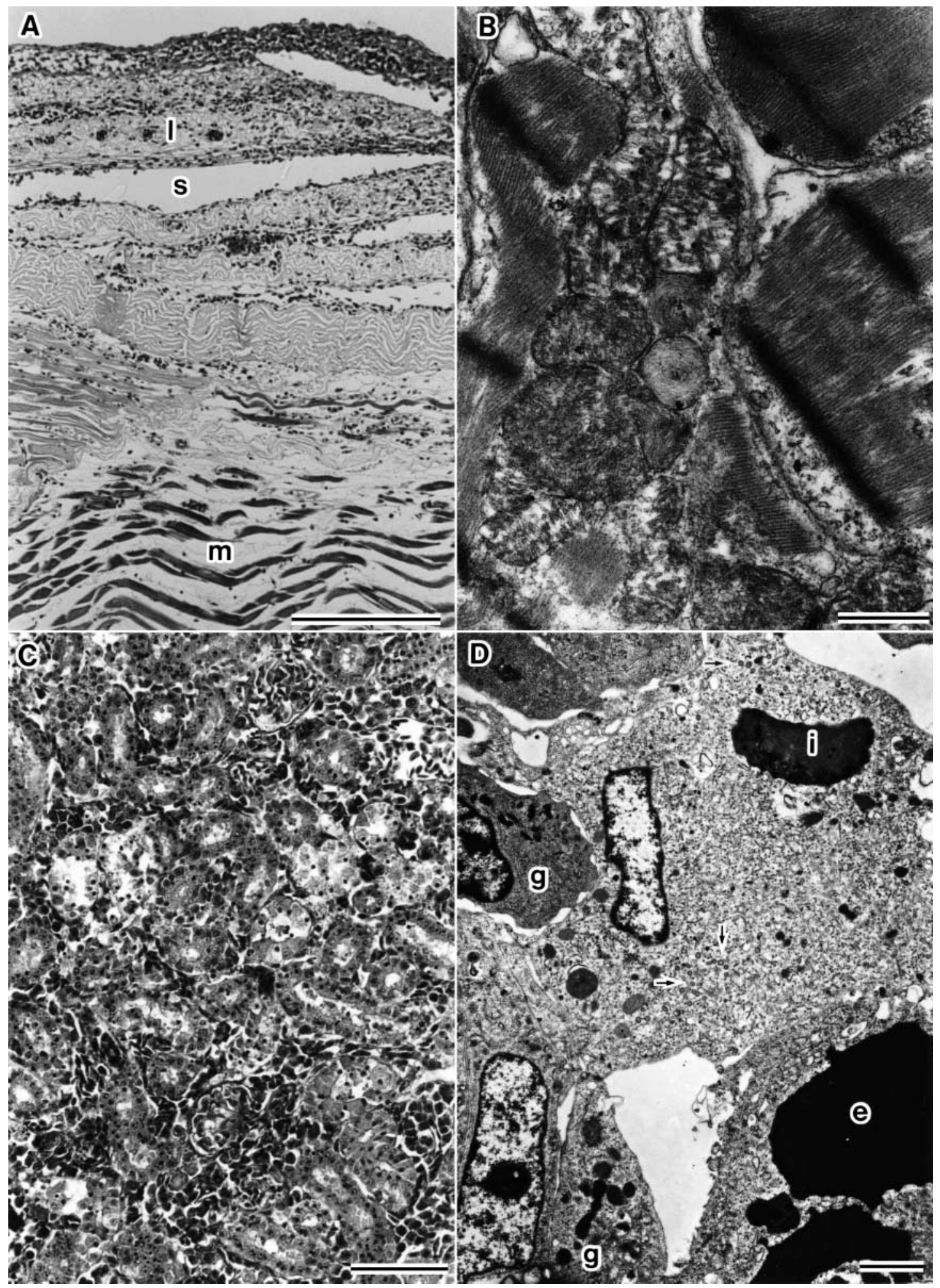

Fig. 7. Cyprinus carpio. (A-D) Experimentally diseased fish that showed skin ulcers. (A) In an anasarcous skin lesion, the dermis and the lateral musculature are extensively edematous and hemorrhagic. H\&E. Scale bar $=200 \mu$ m. (B) Electron micrograph of cardiac muscle fibers. Bundles of myofibrils are fragmented showing the swollen banding pattern. Mitochondria possess fragmented cristae. Glycogen granules disappear. Scale bar $=1 \mu \mathrm{m}$. (C) In the kidney, most of tubular epithelial cells are necrotized and destroyed. H\&E. Scale bar $=100 \mu \mathrm{m}$. (D) Electron micrograph of hematopoietic tissue. A necrotized cell contains many CLV particles (arrows), electron-dense materials containing crystalline inclusions and tubular structures. A macrophage phagocytizes an erythrocyte. Acidophilic granular cells have increased in number. Scale bar $=2 \mu \mathrm{m}$. e: fragments of a phagocytized erythrocyte; g: acidophilic granular cells; i: electron-dense materials containing crystalline inclusions; l: dermal loose connective tissue; m: lateral musculature; s: scale-sac from which a scale was removed 
mus and ascites in addition to the formation of skin ulcers. These anasarcous changes were not observed in diseased carp that were infected only with CLV. (Miyazaki et al. 2000). In contrast, infection with $A$. hydrophila alone caused anasarcous changes and dermal hemorrhage but none of the skin ulcers in carp (Kusuda \& Takahashi 1970, Kanai \& Takagi 1986). In transmission experiments by cohabitation with naturally diseased carp, experimental carp in which the skin had been injured were moribund and exhibited 1 of 2 different types of external features: no external signs, or both anasarcous signs and skin ulcers. In the moribund fish with no external signs, there was severe damage of cardiac muscles, and extensive necrosis in the spleen and hematopoietic tissues. In addition to successful isolation of CLV from examined organs, EM revealed many CLV particles in these necrotic cells. These results indicate that these carp were moribund due to viremia with CLV. The symptoms of these fish were the same as those of fish artificially infected with an intra-abdominal inoculation with cultured CLV (Miyazaki et al. 2000). Naturally diseased fish possessed fibrocytes and capillary endothelial cells containing CLV particles in the dermis. CLV appears to be released into the water through the damaged epidermis. Thus, healthy fish placed with naturally diseased carp acquire the virus through slight wounds in their skin. Such a manner of viral transmission appears to occur in fish farming ponds as well as in aquaria.

In contrast, experimentally diseased carp that displayed anasarcous signs in addition to skin ulcers showed hemorrhage in the myocardium, degenerated hepatocytes, nephroses and hemosiderosis. EM revealed CLV particles in fibrocytes of dermis lesions, cardiac muscle fibers, splenocytes and hematopoietic cells, which determines a CLV infection. Hemosiderosis appears to be induced by hemolysis. Because the isolates of Aeromonas hydrophila have a hemolytic activity, the hemosiderosis is evidence of an A. hydrophila infection, which was found in crucian carp suffering from an Aeromonas hydrophila infection (Miyazaki \& Kaige 1986). Therefore, the combined infection of CLV and A. hydrophila was also replicated by cohabitation experiments. These pathogenic agents appear to invade healthy carp through slight damage to the skin.

As well as hemolysis, anasarcous changes have been revealed to be caused by toxic substances which were produced in vivo. Carp that had been intramuscularly injected with Aeromonas hydrophila showed both hemolysis and anasarcous changes (Kanai \& Takagi 1986). These changes were caused by toxic substances produced by the bacterium. The nephroses, hepatocyte degeneration and cardiac hemorrhage that were observed in the present study appear to have been caused by aeromonad toxins because EM showed no evidence of bacterial cells invading these tissues. The toxins appear to have been produced by bacteria that grew in edematous scale-sacs and ascitic fluid as well as skin ulcerative lesions. Capillaries in dermal lesions were partially damaged and allowed hemorrhage as well as exudation of plasma containing fibrin. Thus, anasarcous changes were caused by damaged capillaries that appear to be due to bacterial toxin. In a preliminary infectivity test with an isolate of $A$. hydrophila, the inoculation at a level of $10^{8} \mathrm{CFU} \mathrm{ml}^{-1}$ caused acute mortality of the injected fish. However, as shown by the present results, the bacterium when inoculated at lower levels of $10^{5} \mathrm{CFU} \mathrm{ml}^{-1}$ neither grew within the fish nor caused mortality, although the isolates displayed a high hemolytic activity on sheep-blood agar plates. These results indicate that the isolates by themselves have weak pathogenicity, and therefore their pathogenic properties are facilitated in fish that have been suffering from a CLV infection. It is interesting that diseased fish that had the combined infection sometimes lived longer than did fish with the CLV infection alone. This phenomenon suggests that some aeromonad toxin reduces the activity of CLV in order to prevent acute death of fish, or it appears to induce a kind of interferon preventing replication of CLV as bacterial toxins do in mammals (Imanishi 1997) because it is known that fish produce cytokine or cytokine-like substances (Secombes et al. 1999, Zou et al. 2000). In the combined infection, acute death due to a virus infection appears to prevent good multiplication of the bacterium within live fish. We are presently conducting studies to better understand the interrelation between CLV and A. hydrophila and studies on aeromonad toxins. It has been revealed that the toxins are produced more efficiently in LB broth with $5 \%$ carp serum than in HI broth. The toxins cause anasarcous changes, hemolysis, and cellular damages in injected carp. These results will be presented in future papers.

Acknowledgements. This study was supported by a grant from the Japan Varicolored Carp Promotion Society.

\section{LITERATURE CITED}

Aoki T (1974) Studies of drug-resistant bacteria isolated from water of carp-ponds and intestinal tracts of carp. Bull Jpn Soc Sci Fish 40:247-254 (in Japanese)

Aoki T (1975) Effects of chemotheraputics on bacterial ecology in the water of ponds and the intestinal tracts of cultured fish, ayu (Plecoglossus artiveris). Jpn J Microbiol 19: $7-12$

Fijan NN (1972) Infectious dropsy in carp-A disease complex. In: Mawdesley-Thomas LE (ed) Disease of fish. Academic Press, London, p 39-51

Fijan NN, Petrinec Z, Sulimanovic D, Zwillenberg LO (1971) 
Isolation of the viral causative agent from the acute form of infectious dropsy of carp. Vet Arhiv 41:125-138

Imanishi J (1997) Interferons. In: Hatanaka S (ed) Virology. Asakura-shoten, Tokyo, p 158-166

Kanai K, Takagi Y (1986) Alpha-hemolytic toxin of Aeromonas hydrophila produced in vivo. Fish Pathol 21: 245-250

Kanai K, Wakabayashi H, Egusa S (1977) Comparison of intestinal microflora between healthy and diseased pondcultured eels. Fish Pathol 12:199-204

Kubota SS, Miyazaki T, Egusa S (1981) Color atlas of fish histopathology, Vol 1. Shin-suisan-shinbun-sha, Tokyo

Kusuda R, Takahashi Y (1970) Studies on the scale protrusion disease of carp fishes-1. Characteristics of Aeromonas liquefaciens isolated from diseased fishes. Fish Pathol 4: 87-97

Miyazaki T (1980) Histopathological study on bacterial in-

Editorial responsibility: Jo-Ann Leong,

Corvallis, Oregon, USA fections in fishes. Bull Fac Fish Mie Univ 7:63-149 (in Japanese)

Miyazaki T, Kaige N (1986) A histopathological study on motile aeromonad disease of crucian carp. Fish Pathol 21: 181-185

Miyazaki T, Okamoto H, Kageyama T, Kobayashi T (2000) Viremia-associated ana-aki-byo. A new viral disease in color carp Cyprinus carpio in Japan. Dis Aquat Org 39: 183-192

Secombes CJ, Zou J, Laing K, Daniels GD, Cunningham C (1999) Cytokine genes in fish. Aquaculture 172:93-102

Sorimachi M, Egusa S (1971) Aerobic bacteria in the intestines of pond-cultured eels. Fish Pathol 6:1-7 (in Japanese)

Zou J, Holland J, Pleguezuelos O, Cunningham C, Secombes CJ (2000) Factors influencing the expression of interleukin-1 $\beta$ in cultured rainbow trout (Oncorhynchus mykiss) leukocytes. Dev Comp Immun 24:575-582

Submitted: June 3, 2000; Accepted: August 22, 2000

Proofs received from author(s): February 9, 2001 